\title{
Pengaruh Electronic Wallet terhadap Kegiatan Keuangan Indonesia (Perbandingan Aplikasi Electronic Wallet Milik Perusahaan Financial Technology terhadap Aplikasi Electronic Wallet milik BUMN)
}

\author{
Nonika Inggiharti \\ Fakultas Hukum Universitas Indonesia \\ Email : inggiharti.nonika@yahoo.com
}

\begin{abstract}
This paper aims to describe the effect of changes in the payment system with an electronic wallet to financial activities in Indonesia and to compare the likelihood of losses for the state against transactions using electronic technology companies' electronic wallets to stateowned electronic wallets. The approach to be used is empirical juridical. By using primary data as main data. Based on these data, the analytical method used by processing data, and supported by secondary data through qualitative analysis. Based on the results of this study there are several things, namely, first, the use of electronic wallets has a positive impact in the form of efficiency, and reducing the risk of criminal acts. The risk of the possibility of inflation and rupiah depreciation can only be avoided by following the provisions set by Bank Indonesia and the Financial Services Authority through PBI Number 20/6/2018 regarding Electronic Money. There is a need to increase the ability to compete with SOE electronic wallet applications to minimize the possibility of rupiah depreciation and oversight by financial institutions.
\end{abstract}

Keywords : Electronic Wallet; Financial Technology; Regulation; Transaction.

\begin{abstract}
ABSTRAK
Tulisan ini bertujuan untuk menguraikan pengaruh perubahan sistem pembayaran dengan electronic wallet terhadap kegiatan keuangan di Indonesia serta membandingkan kemungkinan kerugian bagi negara terhadap transaksi menggunakan electronic wallet milik perusahaan financial technology terhadap electronic wallet milik BUMN. Pendekatan yang akan digunakan adalah yuridis empiris. Dengan menggunakan data primer sebagai data utama. Berdasarkan data tersebut, metode analisis yang digunakan dengan mengolah data, dan didukung dengan data sekunder secara analisis kualitatif. Berdasarkan hasil penelitian ini terdapat beberapa hal yaitu, pertama, penggunaan electronic wallett memberikan dampak positif berupa efisiensi, dan pengurangan resiko terjadinya tindak pindana. Resiko kemungkinan terjadinya inflasi serta pengendapan rupiah hanya dapat dihindari dengan mengikuti ketentuan yang telah diatur oleh Bank Indonesia dan Otoritas Jasa Keuangan melalui PBI Nomor 20/6/2018 tentang Uang Elektronik. Perlu adanya peningkatan kemampuan bersaing aplikasi electronic wallet milik BUMN guna memperkecil kemungkinan pengendapan rupiah serta pwngawasan lebih oleh lembaga keuangan.
\end{abstract}

Kata Kunci: Electronic Wallet; Financial Technology; Peraturan; Transaksi. 


\section{Pendahuluan}

Dinamika kehidupan masyarakat dewasa ini, telah melahirkan pola pemikiran baru yang turut berkembang seiring dengan kemajuan zaman. Ketika mekanisme pembayaran dituntut untuk selalu mengakomodir setiap kebutuhan masyarakat dalam hal perpindahan dana secara cepat, aman dan efisien, maka inovasi-inovasi teknologi pembayaran semakin bermunculan dengan sangat pesat sehingga sektor keuangan yang terdiversifikasi dengan baik yang memiliki bank maupun lembaga keuangan non-bank (LKNB) yang sehat - merupakan kunci untuk mendukung tujuan pembangunan yang telah diuraikan oleh Pemerintah Indonesia, yaitu peningkatan pertumbuhan ekonomi, penciptaan lapangan kerja yang lebih luas, dan perbaikan taraf hidup bagi rakyat Indonesia. Bank dan LKNB sama-sama merupakan unsur kunci untuk sistem keuangan yang sehat dan stabil, saling melengkapi dan menawarkan sinergi. ${ }^{1}$ Tren pergeseran dari penggunaan paper based instrument seperti cek dan bilyet giro ke penggunaan card based dan electronic based instrument terlihat dari semakin terbiasanya masyarakat menggunakan alat pembayaran seperti kartu kredit, kartu ATM/Debet, transfer elektronik melalui kliring dan Real Time Gross Settlement (RTGS), Scripless Securities Settlement System (SSSS), uang elektronik baik yang berbentuk kartu (card based) maupun server based, pembayaran melalui saluran internet banking mobile payment dan fitur-fitur turunan lainnya. Walaupun tak dapat dipungkiri, ada segmen masyarakat tertentu yang masih atau lebih nyaman menggunakan cek/Bilyet Giro (BG). ${ }^{2}$

Penguatan infrastruktur tersebut tercermin dimana Bank Indonesia sebagai penyelenggara sistem pembayaran mulai mengoperasikan layanan setelment Payment-versusPayment (PvP) pada Sistem Bank Indonesia Real Time Gross Settlement (Sistem BI-RTGS). Layanan penyelesaian setelmen dari transaksi jual beli valuta asing khususnya United States Dollar (USD) terhadap Indonesian Rupiah (IDR) dilakukan secara bersamaan. Hal ini untuk menghindari terjadinya risiko kegagalan setelmen pada saat pertukaran nilai uang dilakukan. Selain itu dengan kecenderungan transaksi pembayaran ke depan yang semakin tiada batas sudah barang tentu memunculkan kebutuhan likuiditas yang semakin tinggi bagi para pelaku ekonomi, antara lain munculnya ragam derivasi produk keuangan global dan hilangnya batasan wilayah ekonomi regional yang digagas melalui MEA maupun kerjasama regional

\footnotetext{
${ }^{1}$ Membuka Potensi Sumber Daya Keuangan Dalam Negeri: Peran Lembaga Non Bank, http://siteresources .worldbank.org/INTINDONESIA/Resources/Publication/280016-1168483675167/NBFIExe_Bhs.pdf, diakses pada tanggal 15 Februari 2020.

${ }^{2}$ Perkembangan Sistem Pembayaran di Indonesia, https://www.bi.go.id/id/sistem-pembayaran/diindonesia/perkembangan/Contents/Default.aspx, diakses tanggal 15 Februari 2020.
} 
lainnya. Selain PvP, penguatan infrastruktur lainnya adalah penyatuan penyelenggaraan fungsi setelmen surat berharga BI-SSSS ke dalam penyelenggaraan fungsi sistem pembayaran dan setelmen di Bank Indonesia (Sistem BI-RTGS). Penyatuan tersebut dimaksudkan untuk meningkatkan efisiensi penyelenggaraan kegiatan setelmen dana dan surat berharga berikut infrastruktur dan sumber daya manusia yang pada akhirnya dapat meningkatkan kualitas layanan Bank Indonesia kepada stakeholders terkait. ${ }^{3}$

Marc Hollander mengemukakan terdapat dua tipe/ jenis produk uang elektronik dengan karakteristiknya sebagai berikut: ${ }^{4}$

"Two types of e-money products exist: (1) Card-based products, also known as prepaid cards (and often called electronic purse or electronic wallet), are designed for making face-to-face payments of small value (such as at newspaper stands, in bakeries, etc) and for use in vending machines and parking meters. The prepaid value is typically stored in a microprocessor chip embedded in a plastic card. Electronic purses are intended to complement rather than substitute for traditional retail payment instruments such as debit and credit cards. They are, however, in direct competition with coins and (small denomination) banknotes. Prepaid cards are intended to be used as a general, multipurpose means of payment, in contrast to the many existing singlepurpose cards (such as those used for public transport) which are not considered emoney. (2) Network-based or software-based products use telecommunication networks, such as the internet, to make small-value payments, usually as a substitute for credit cards. Network-based products use specialised software installed on a standard personal computer or laptop for storing the value".

Beradasarkan pendapat Marc Hollander maka uang electronic wallet merupakan produk berbasis software yang menggunakan sinyal internet. Indonesia mulai mengenal electronic wallet atau dompet elektronik adalah alat pembayaran digital atau alat pembayaran digital yang menggunakan media elektronik berupa server based. Dampak positif terhadap pelaksanaan kegiatan uang elektronik adalah mewujudkan berkurangnya peredaran uang tunai atau disebut sebagai less cash society ${ }^{5}$ serta keefesienan sebagai alat bayar. Pada umumnya e-Wallet berupa aplikasi yang berbasis di server dan dalam proses pemakaiannya memerlukan sebuah koneksi terlebih dulu dengan penerbitnya. Terdapat beberapa $e$-Wallet yang saat ini ada di pasar yaitu T-Cash Telkomsel, XL Tunai, Rekening Ponsel CIMB Niaga, BBM Money Permata Bank, DOKU, dan lain sebagainya ${ }^{6}$ yang merupakan bagian sistem electronic payment. Electronic Payment adalah sistem pembayaran yang menggunakan media

\footnotetext{
${ }^{3}$ Ibid.

${ }^{4}$ Rachmadi Usman, "Karakteristik Uang Elektronik Dalam Sistem Pembayaran”, Yuridika Universitas Airlangga, Volume 32, Nomor 1, Januari 201, hlm 141

${ }^{5}$ Rifqy Tazkiyyaturrohmah, “Eksistensi Uang Elektronik Sebagai Alat Transaksi Keuangan Modern”, Muslim Heritage, Volume 3, Nomor 1, Mei 2018, hlm 24.

${ }^{6} \mathrm{PPG}$ DALAM JABATAN," PPG SPADA RISTEKDIKTI, https://ppg.spada.ristekdikti.go.id /master/mod/resource/view.php?id=7942, diakses pada tanggal 15 Februari 2020
} 
internet sebagai komunikasi. Banyak perusahaan yang menyediakan pihak penjual dan pembeli dengan memberikan jaminan keamanan transaksi elektronik. Untuk menjamin keamanan transaksi tersebut, perusahaan yang menjadi perantara akan bekerja sama dengan sejumlah lembaga perbankan untuk mulai memfasilitasi e-payment secara aman, cepat dan praktis. $^{7}$ Keterlibatan Indonesia dalam forum-forum ekonomi dunia juga telah sedikit mempengaruhi kebijakan ekonomi di Indonesia, salah satunya adalah kebijakan mengenai sistem pembayaran. Di Indonesia sistem pembayaran secara umum masih menggunakan uang tunai sebagai alat pembayaran, padahal dengan banyaknya uang yang beredar di masyarakat dapat memicu meningkatnya inflasi. Inilah yang membuat beberapa negara lain seperti Jepang, Singapura, Inggris dan Amerika Serikat sudah terlebih dahulu menerapkan sistem pembayaran menggunakan uang elektronik. ${ }^{8}$ Pertumbuhan Transaksi Uang Elektronik di Indonesia sampai dengan Tahun 2020 ini dapat digambarkan sebagaimana berikut: ${ }^{9}$

Tabel 1. Transaksi Uang Elektronik di Indonesia Periode 2015-2020

\begin{tabular}{|l|c|c|}
\hline Periode & Volume & Value \\
\hline 2015 & $535,579,528$ & $5,283,018$ \\
\hline 2016 & $683,133,352$ & $7,063,689$ \\
\hline 2017 & $943,319,933$ & $12,375,469$ \\
\hline 2018 & $2,922,698,905$ & $47,198,616$ \\
\hline 2019 & $5,226,699,919$ & $145,165,468$ \\
\hline $\begin{array}{l}2020 \\
\text { (Jan-Apr) }\end{array}$ & $1,615,299,688$ & $63,639,247$ \\
\hline
\end{tabular}

Electronic wallet berbasis aplikasi di Indonesia bukan hanya milik perusahaan financial technology tetapi juga terdapat satu aplikasi electronic wallet milik BUMN.

\footnotetext{
${ }^{7}$ Kekurangan Tunai vs Keuntungan Nontunai," 16 Februari 2017, http://www.nontunai.com/kekurangan-tunaivskeuntungan-nontunai/, diakses pada tanggal 15 Februari 2020.

${ }^{8}$ Rifqy Tazkiyyaturrohmah, Op.Cit, Hlm 23

${ }^{9}$ Bank Indonesia, Jumlah Transaksi Uang Elektronik Beredar, https://www.bi.go.id/id/pencarian/Default.aspx?k=Transaksi\%20Uang\%20Elektronik, diakses pada tanggal 18 Juni 2020.
} 


\section{Table 2. Daftar Dompet Digital ${ }^{10}$}

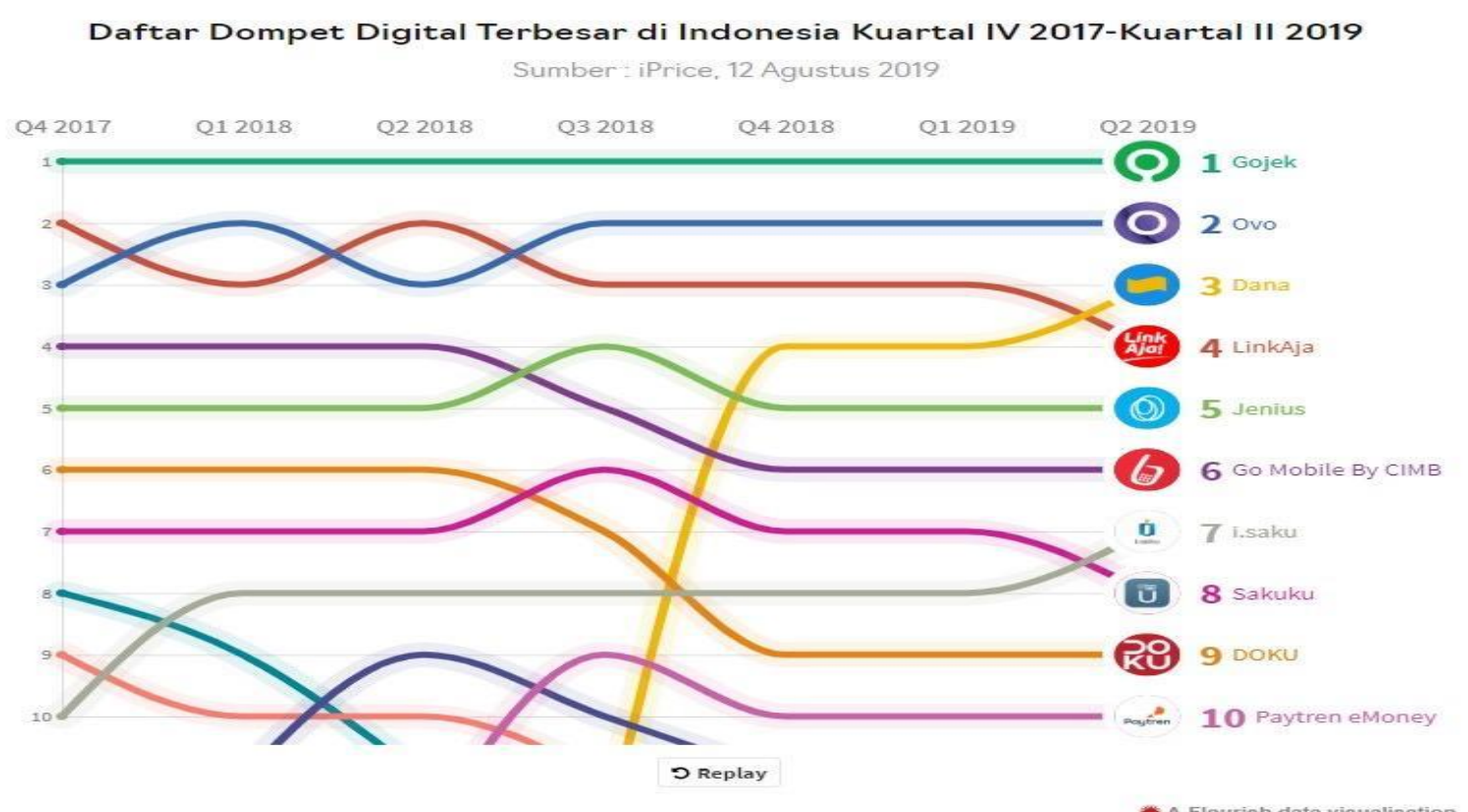

Dimulai pada tahun 2017 telah membuktikan kehadiran Go-Pay telah menduduki tempat pertama sebagai uang elektronik terpopuler ${ }^{11}$, kemudian berkembang bukan hanya dapat sebagai alat bayar pemesanan dengan aplikasi Gojek tetapi seiring waktu, Go-pay dapat dikategorikan sebagai electronic wallet karna telah dapat digunakan sebagai alat bayar dengan beberapa outlet seperti alfamart, PLN, dan lain sebagainya serta dapat melakukan penarikan saldo Go-pay menjadi bentuk uang kartal melalui sistem withdraw. Hal ini terlihat dengan peringkat pertama adalah gopay, sebagai salah produk dari startup decacorn pertama di Indonesia Go-Jek menjadi aplikasi e-wallet dengan pengguna aktif terbanyak di Indonesia. Walaupun aplikasi Go-jek tidak digolongkan dalam aplikasi finance di App Annie, menurut informasi dari Medium 30\% dari total transaksi uang elektronik di Indonesia berasal dari GoPay. Februari 2019, Go-Pay berhasil menyentuh angka transaksi sebesar USD 6.3 miliar dengan total $70 \%$ didapatkan dari transaksi Go-Jek menggunakan Go-Pay sebagai metode pembayaran ${ }^{12}$ dan peringkat keempat aplikasi milik BUMN yaitu link aja, merupakan aplikasi e-wallet gabungan berbagai BUMN (Badan Usaha Milik Negara) yaitu T-Cash milik Telkomsel, Mandiri e-cash milik Bank Mandiri, UnikQu milik BNI, T-Money

\footnotetext{
10 Daftar Dompet Digital, https://databoks.katadata.co.id/datapublish/2019/08/23/inilah-daftar-dompet-digitalterbesar-di-indonesia, diakses pada tanggal 15 Februari 2020.

${ }^{11}$ Databoks Katadata Indonedia, "GoPay Uang Elektronik Terpopuler di Indonesia," dikutip dari https://databoks.katadata.co.id/datapublish/2018/02/13/go-pay-uang-elektronik-terpopuler-di-indonesia diakses pada tanggal 21 Februari 2020

${ }^{12}$ Dompet elktronik di Indonesia, https://iprice.co.id/trend/insights/e-wallet-terbaik-di-indonesia/, diakses pada tanggal 15 Februari 2020.
} 
milik Telkom dan T-Bank milik BRI. Migrasi ini dimulai sejak 30 Juni 2019, LinkAja resmi menjadi saingan Go-Pay dan OVO yang sudah lebih dulu terjun di dunia fintech, dengan total 22 juta pengguna yang sudah terdaftar.

Dengan pembayaran bersistem elektronik memberikan resiko terhadap berkurangya peredaraan rupiah Indonesia. Menurut golongan Keynesian terdapat dua pendapat penyebab inflasi dari sudut permintaan, pertama, penyebab utama inflasi adalah kelebihan penawaran uang $^{13}$. Menurut David Ricardo "kuat atau lemahnya nilai uang sangat bergantung pada jumlang uang. Apabila jumlah uang berubah menjadi dua kali lipat maka nilai uang akan menurun menjadi setengah dari semula. Sebaliknya apabila jumlah uang berkurang hingga setengah maka nilai uang akan naik menjadi dua kali lipat. Hal ini terjadu karena jika jumlah uang naik menjadi dua kali lipat, otomatis nilai uang akan menurun mejadi setngahnya." 14 serta resiko terjadinya pengendapan uang pada perusahaan financial technology yang kepemilikan sahamnya dimiliki oleh investor-investor asing. Tulisan ini bertujuan untuk melihat sejauhmana pengaruh electronic wallet milik perusahaan financial technology dan milik BUMN terhadap kegiatan keuangan dan bagaimana Peraturan Perundang-Undangan mengatur mengenai batasan pembayaran dengan electronic wallet sebagai bagaian financial technology untuk mencegah terjadinya kerugian terhadap keuangan Nasional.

\section{Metode}

Metode pendekatan yang digunakan dalam penelitian ini adalah metode pendekatan yuridis empiris, yaitu penelitian hukum mengenai pemberlakuan atau implementasi ketentuan normatif pada setiap peristiwa hukum tertentu yang terjadi dalam masyarakat. ${ }^{15}$ Penelitian yuridis empiris dalam tulisan ini adalah penelitian lapangan terhadap data primer untuk meneliti peraturan-peraturan perundang-undangan yang kemudian didukung dengan data pendukung sebagai bukti lapagan. Penelitian ini akan menganalisis bagaiaman pengaruh kedua variabel yaitu, electronic wallet milik perusahaan financial technology dan electronic wallet milik BUMN dengan data berupa statistic dan laporan Bank Indonesia dan implementasi Peraturan Bank Indonesia Nomor 20/6/2018 tentang Uang Elektronik.

\footnotetext{
13 Adrian Sutawijaya, “Pengaruh Faktor Ekonomi Terhadap Inflasi di Indonesia," Volume 8 Nomor 2, Maret 2012, hlm 88.

${ }^{14}$ Aulia Annaisabiru, Teori Permintaan dan Penawaran Uang, https://blog.ruangguru.com/ekonomi-kelas-11teori-permintaan-dan-penawaran-uang, diakses pada tanggal 15 Februari 2020.

${ }^{15}$ Abdulkadir Muhammad, Hukum dan Penelitian Hukum, Bandung:Citra Aditya Bakti, 2004,hlm 134.
} 


\section{Anilisis dan Pembahasan}

\section{Perbandingan Pengaruh Electronic Wallet Perusahaan Financial Technology} terhadap Electronic Wallet BUMN mengacu pada Peraturan Bank Indonesia Nomor 20/6/2018 tentang Uang Elektronik dan Peraturan OJK Nomor 13/POJK.02/2018 tentang Inovasi Keuangan Digital di Sektor Jasa Keuangan.

Electronic wallet adalah atau dompet elektronik adalah "E-wallet is a type of electronic card which is used for transactions made online through a computer or a smartphone. Its utility is same as a credit or debit card. An E-wallet needs to be linked with the individual's bank account to make payments" ${ }^{\prime 16}$ E-wallet sendiri mulai berkembang di Indonesia pada tahun 2018 diiringi dengan perkembangan aplikasi $e$ money. Sering berkembangnya zaman, electronic money yang dapat digunakan sebagai alat pemayaran melalu aplikasi adalah uang elektroik milik Telkomsel yaitu T-cash yang diterbitkan pada Tahun 2007 dengan melakukan registrasi. Kemudian pada tanggal 30 Juni 2019 beberapa perusahaan Badan Usaha Milik Negara (BUMN) yang memiliki produk uang elektronik yaitu, UnikQu Bank Negara Indonesia, T- Cash milik Telkomsel, e-cash milik Bank Mandiri, T-Money milik Telkom, dan T-Bank milik Bank Rakyat Indonesia. Namun munculnya aplikasi electronic wallet sebagai suatu alat bayar yang diterbitkan oleh BUMN setelah terbitnya electronic wallet oleh perusahaan financial technology. Untuk menyeimbangkan persaingan yang terjadi antar perusahaan financial technology. Beberapa lectronic wallet yang dikeluarkan oleh lembaga selain bank yaitu dalam hal ini perusahaan financial technology diantaranya, OVO milik Lippo Group. Pada dasarnya electronic wallet adalah dompet elektonik yang digunakan sebagai menyimpan dana uang elektronik yang dapat digunakan sebagai alat bayar.

Uang dalam electronic wallet itu sendiri adalah uang elektronik yang telah diterbitkan berdasarkan pengajuan izin terlebih dahulu berdasarkan Pasal 8,9 dan 10 ayat 1 dan 2 Peraturan Bank Indonesia Nomor 20/6 2018 tentang Uang Elektronik yaitu;

"Pasal 8: Lembaga Selain Bank yang mengajukan permohonan izin sebagai Penerbit harus memenuhi persyaratan modal disetor minimum dan komposisi kepemilikan saham.",17

\footnotetext{
${ }^{16}$ Definisi dompet elektronik, https:// economictimes.indiatimes.com/definition/e-wallets, diakses pada tanggal 18 Februari 2020.

${ }^{17}$ Peraturan Bank Indonesia Nomor 20/6/2018 Tentang uang Elektronik Tambahan Lembar Negara Republik Indonesia nomor 6203
} 
"Pasal 9: (1) Modal disetor sebagaimana dimaksud dalam Pasal 8 paling sedikit sebesar Rp 3.000.000.000,00 (tiga milyar rupiah). (2) Lembaga Selain Bank yang telah memperoleh izin sebagai Penerbit wajib tetap memelihara pemenuhan modal disetor minimum sebagaimana dimaksud pada ayat (1) dan menyesuaikan pemenuhan modal disetor berdasarkan posisi Dana Float sesuai dengan ketentuan sebagaimana dimaksud dalam Pasal 50.",18

"Pasal 10: (1) Komposisi Kepemilikan saham sebagaimana dimaksud dalam Pasal 8 yaitu paling sedikit 51\% (lima puluh satu persen) sahamnya dimiliki oleh: a. warga negara Indonesia; dan/atau b. badan hukum Indonesia. (2) Dalam hal terdapat kepemilikan asing pada Lembaga Selain Bank maka perhitungan porsi kepemilikan asing tersebut meliputi kepemilikan secara langsung maupun kepemilikan secara tidak langsung sesuai dengan penilaian Bank Indonesia.,"19

Pengaruh aliran dana yang masuk ke electronic wallet mempengaruhi kondisi keuangan Indonesia. Pada dasarnya semakin tinggi pengguanaan uang elektronik pasti akan mempengaruhi peredaran uang kartal. Berkurangnya peredaran uang kartal akan meningkatkan penawaran atas uang makan akan memicu indikasi terjadinya inflasi. Jika rupiah yang masuk pada electronic wallet milik perusahaan financial technology yang kepemilikan sahamnya dapat dimiliki oleh investor asing, otomatis akan mempengaruhi arus dana bag Indonesia. Berbeda dengan jika rupiah masuk lebih banyak kedalam electronic wallet milik BUMN. Tidak perlu khawatir juga BUMN akan dikuasai swasta atau pihak asing. Sebab, pasar modal memberikan keleluasaan terkait mekanisme pelepasan saham. Pemerintah bisa menahan porsi kepemilikan dari BUMN tercatat sebagai pemegang saham yang paling besar seperti BUMN tercatat yang ada saat ini. Selain itu pemerintah juga memiliki saham khusus yang disebut saham dwi warna yang memberikan kewenangan bagi pemegangnya untuk mengontrol penuh perusahaan, ${ }^{20}$ walaupun terdapat porsi kepemilikan bagi swasta dana sing dimungkan kan namun pemerintah tetap dapat mengontrol sebagai pemilik saham mayor. ${ }^{21}$

Dengan pengaturan mengenai kepemilikan saham dalam hal penerbitan uang elektronik dan/atau wewenang untuk melaksanakan kegiatan financial technology salah satunya adalah electronic wallet mengantisipasi terjadi kerugian yang diakibatkan pada tingginya aliran rupiah yang masuk yang berindikasi terjadinya pengendapan dana ke asing. Namun prakteknya kepemilikan saham yang diatur oleh Bank Indonesia sendiri

\footnotetext{
${ }^{18}$ Ibid.

${ }^{19}$ Peraturan Bank Indonesia Nomor 20/6/2018 Tentang uang Elektronik Tambahan Lembar Negara Republik Indonesia nomor 6203

${ }^{20}$ Asing Tidak Bisa Kuasi BUMN Terbuka, Media DJKN, https://www.djkn.kemenkeu.go.id/berita_media/baca/12680/Asing-Tidak-Bisa-Kuasai-BUMN-Terbuka.html, diakses pada tanggal 19 Februari 2020

21 Ibid.
} 
berdasarkan pasal 10 Peraturan Bank Indonesia Nomor 20/6/2018 yang mengatur bahwa "kepemilikan saham minimal 51\% (lima puluh satu persen) dimiliki oleh; a. warga negara Indonesia; dan/atau b. badan hukum Indonesia." 22 Berdasarkan pernyatan Mochtar Riady, pendiri sekaligus pemilik Lippo Grup mengungkapkan bahwa telah menjual sekitar 70\% menjual saham OVO, "Bukan melepas, kami menjual sebagian. Sekarang (saham) kami mungkin tinggal 30 persen. Dua pertiga kami jual". ${ }^{23}$

Selain mengenai resiko cash flow ke investor asing, sebenarnya penggunaan electronic wallet, timbul opini berkurangnya permintaan rupiah sehingga meningkatkan penawaran uang, jika pada akhirnya Indonesia mengalami hal ini, maka dikhawatirkan akan timbul indikasi terjadi nya inflasi terhadap keuangan nasional. Selain itu dalam aspek privasi yang menjadi resiko lain dari penggunaan electronic wallet (e-wallet) adalah masalah privasi, terlebih apabila aplikasi tersebut di miliki oleh lembaga bukan keuangan yang ditakutkan bahwa kerahasian informasi pribadi para konsumen tidak dapat terjaga dengan baik kerahasiannya.

\section{Pengaturan Bank Indoenesia dan Otoritas Jasa Keuangan dalam Electronic Wallet.}

Dasarnya Bank Indonesia telah mengatur secara jelas beberapa hal yang memang dirasa penting dalam pelaksanaan kegiatan finansial technology, baik dari pihak-pihak yang telah diatur secara jelas, dipahami bahwa setiap orang yang telah diberikan izin oleh Bank Indonesia untuk dapat melakukan kegiatan financial technology telah memenuhi persyaratan serta menyetujui segala sesuatu yang disyaratkan oleh Bank Indonesia. Hal krusial yang telah diatur oleh Bank Indonesia untuk mencegah terjadinya resiko dari kemajuan teknologi terhadap sistem keusangan dalam hal ini electronic wallet adalah mengenai kepemilikan saham. Bank Indonesia pada dasarnya telah menyadari bahwa dibalik diperbolehkannya penerbitan dan pelaksanaan uang elektronik terdapat resiko yang harus dicegah. Sehingga berdasarkan pasal 10 ayat 1 Peraturan Bank Indonesia Nomor 20/6/2018 tentang uang elektronik mengatur bahwa kepemilikan 51\% dari saham dimiliki oleh a. warga negara Indonesia; dan/atau b. badan hukum Indonesia. ${ }^{24}$ Yang seharusnya dilakukan sekarang adalah menaati apa yang telah diatur, mencegah terjadi jual beli saham terhadap investor asing yang dapat menyebabkan grafik kepemilikan saham investor asing

\footnotetext{
${ }^{22}$ Peraturan Bank Indonesia Nomor 20/6/2018 Tentang uang Elektronik Tambahan Lembar Negara Republik Indonesia nomor 6203

${ }^{23}$ Mochtar Riady: Saham Kami Tinggal 30 Persen di OVO,

https://www.cnnindonesia.com/ekonomi/20191128131258-92-452278/mochtar-riady-saham-kami-tinggal-30persen-di-ovo, diakses pada tanggal 19 Februari 2020.

${ }^{24}$ Lihat Peraturan Bank Indonesia Nomor 20/6/2018 tentang Uang Elektronik
} 
lebih besar terhadap saham investor dalam negeri. Perlu adanya pengawasan, serta audit yang terus menerus dilakukan terutama terhadap electronic wallet maupun perusahaan financial technology yang diberikan izin menerbitkan dan menghimpun uang elektronik.

Resiko-resiko yang diuraikan diatas akan jauh dapat ditekan atau berkurang jika pengguna electronic wallet milik BUMN lebih banyak dibanding perusahaan financial technology, namu faktanya pada tabel 1.1 yang menggambarkan bahwa jumlah pengguna electronic wallet milik BUMN berada pada peringkat ke empat. ${ }^{25}$

Ketika electronic wallet yang mengauasai saat ini adalah milik perusahaan financial technology yang kepemilikan saham atas asing dapat dilakukan dengan luas sesuai dengan pengaturan hukum investasi, tentu akan mempengaruhi terhadap risiko-risiko yang akan dihadapi Indonesia. Dengan electronic wallet menjadi sasaran utama bagi pengguna tentunya akan menahan atau mencegah terjadinya resiko yang disebabkan dari kegiatan penggunaan electronic wallet ini.

Jika dilihat apakah penggunaan electronic wallet akan mempengaruhi terhadap kondisi peredaran rupiah, berikut data yang dapat diuraikan: ${ }^{26}$

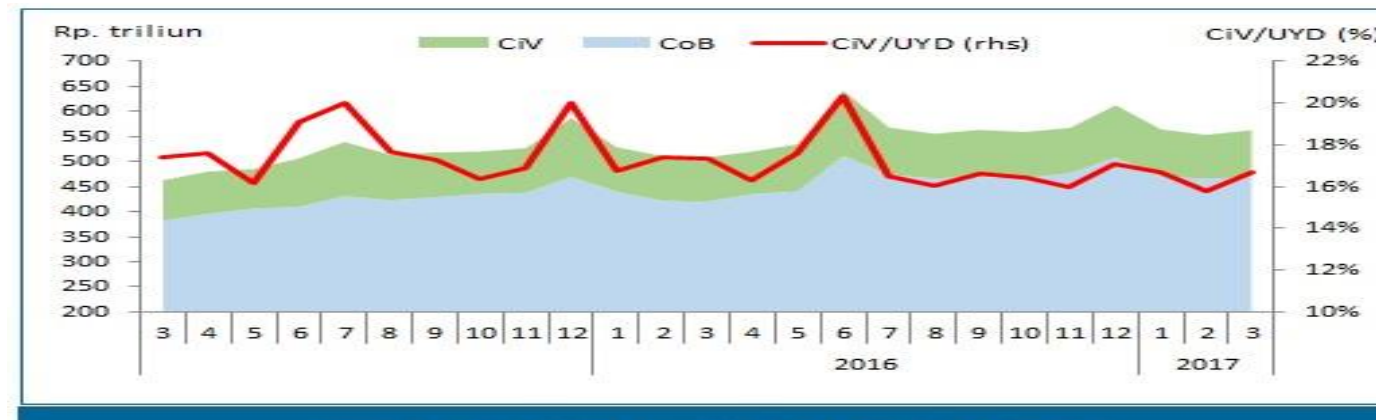

\section{Posisi Uang Kartal yang Diedarkan - Akhir Bulan}

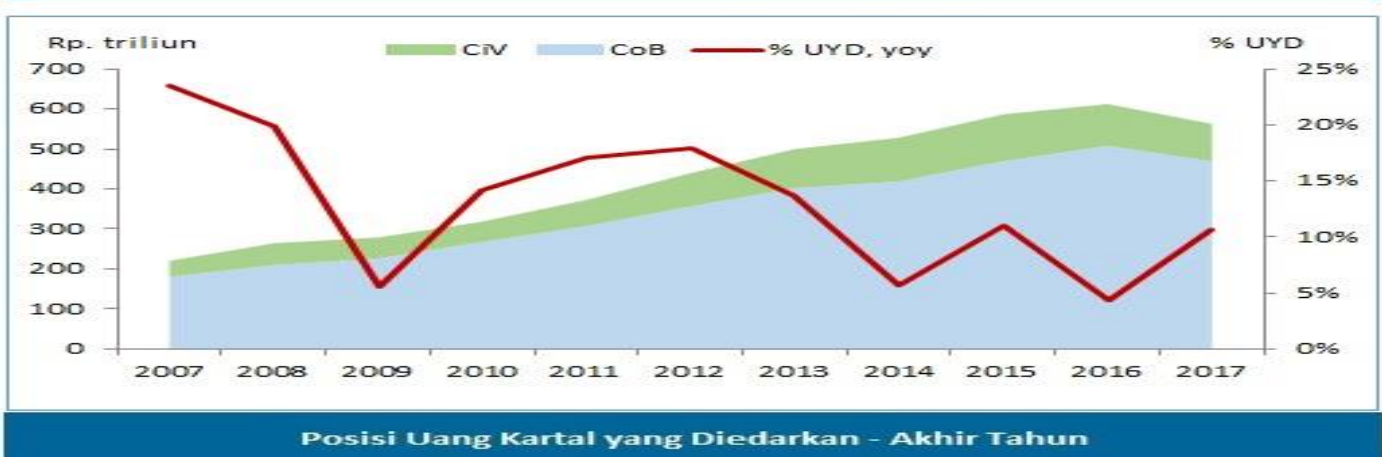

\footnotetext{
${ }^{25}$ Lihat halaman 4

${ }^{26}$ Bank Indonesia, Indikator Sistem Pembayaran, https://www.bi.go.id/id/sistem-pembayaran/indikator/uangkartal/Contents/Default.aspx
} 
Laporan tersebut menunjukan bahwa sampai tahun 2017 kemajuan teknologi dalam sistem pembayaran tidak mempengaruhi permintaan dan peredaran uang dimasyarakat. Hanya saja hal ini lah yang perlu dijaga agar stabilitas keuangan Indonesia terus berjalan dengan baik. Dalam penggunaan electronic wallet berarti mengikatkan diri kepada perusahaan baik perusahaan financial technology maupun BUMN untuk dapat memiliki data pribadi melalui register awal pada akun electronic wallet. Kontrak elektronik telah terjadi disini, kontrak elektronik sendiri adalah "perjanjian para pihak yang dibuat melalui sistem elektronik",27. Sedangkan menurut Edmon Makarim dan Deliana mendefinisikan "kontrak elekronik sebagai perikatan ataupun hubungan hukum yang dilakukan secara elektronik dengan meaduka jaringan (networking) dari sistem informasi yang berbasiskan computer (computer based information system) dengan sistem komunikasi yang berdasarkan atas jaringan dan jasa telekomunikasi (telecommunication based) yang selajutnya difasilitasi oleh keberadaan computer global internet", ${ }^{28}$

Bentuk perjanjian dalam electronic wallet terlihat dari pengguna (user) bersedia memberikan data pribadi, berupa nomor ponsel, nama, dan alamat email pada saat registrasi dan pemberian akses bagi pengguna (user) untuk dapat menikmati fasilitas yang diberikan oleh aplikasi electronic wallet. Disinilah pentingnya Bank Indonesia mengawasi dan mengatur bagaimana agar semua kerahasian data milik pengguna dapat terjaga dengan baik, serta mencegah resiko terjadinya kerugian keuangan dari kegiatan electronic wallet.

\section{Pengaruh Penggunaan Ellectronic Wallet dalam Stabilitas Sistem Keuangan di Indonesia.}

Pada dasarnya belum terdapat definisi baku mengenai Stabilitas Sistem Kuangan sendiri, namun Schinasi mendefiniskan stabilitas keuangan sebagai kondisi dimana sistem keuangan: ${ }^{29}$ (1) Secara efisien memfasilitasi alokasi sumber daya dari waktu ke waktu, dari deposan ke investor, dan alokasi sumber daya ekonomi secara keseluruhan; (2) Dapat menilai/mengidentifikasi dan mengelola risiko-risiko keuangan; (3) Dapat dengan baik menyerap gejolak yang terjadi pada sektor keuangan dan ekonomi.

Secara umum, stabilitas sistem keuangan adalah ketahanan sistem keuangan terhadap guncangan perekonomian, sehingga fungsi intermediasi, sistem pembayaran dan penyabaran risiko tetap berjalan dengan semestinya. Selain itu menurut Deutsche

\footnotetext{
${ }^{27}$ Emma Santi,Budiharto, Hendro Saptono,Pengawasan otoritas, "Jasa Keuangan Terhadap Financial Technology (peraturan Otoritas Jasa Keuangan Nomor 77/POJK.01/2016)”, Diponegoro Law Journal, Volume 6 Nomor 3 Tahun 2017, hlm 7.

${ }^{28}$ Ibid hlm 8.

${ }^{29}$ Bank Indonesia, Stabilitas Sistem Keuangan, Bank Indonesia, Jakarta:2007, Hlm 1
} 
Bundesbank menggambarkan stabilitas keuangan sebagai keadaan seimbang sistem keuangan sehingga berfungsi efisien dalam alokasi sumber dan mengelola risiko dan menjalankan fungsi pembayaran, mampu mengatasi kejutan ekonomi, kebangkrutan dan perubahan struktural yang mendasar. ${ }^{30}$

Pertumbuhan uang non tunai berdasarkan Table 1 mengalami terus peningkatan hal tersbut menggabarkan bahwa perkembangan uang elektronik sangat dipengaruhi oleh kemajuan teknologi yang mendorong perubahan pola hidup masyarakat dan berkembangnya inovasi menambah macam tansaksi non tunai. Pengaruh penggunaan uang non tunai ini mempengaruhi permintaan uang seagaimana dalam teori permintaan uang klasik sebagaimana diuraikan berikut: ${ }^{31}$

\section{$\mathbf{M V}=\mathbf{P T}$}

Dimana $\mathrm{M}$ adalah penawaran uang, $\mathrm{V}$ adalah perputaran uang, $\mathrm{P}$ adalah tingkat harga dan $\mathrm{T}$ adalah volume barang yang diperdagangkan dalam suatu tahun tertentu. Dampak terhadap pembayaran no tunai terhadap stabilitas keuangan menunjukan kecenderungan yang meningkat sebelum krisis, kemudian menurun keika masa krisis dan meningkat kembali pasca krisis, yang diiringi dengan perbaikan kondisi ekonomi. ${ }^{32}$ Selain itu jika mengacu pada teori tersebut diatas menunjukan bahwa apabila Jumlah Uang Beredar (JUBO terlalu banyak beredar maka akan memicu keaikan harga dan kenaikan harga yang terus menerus akan berpotensi menyebabkan inflasi. Dengan penggunaan uang non tunai sebagai suatu alat bayar yang sah, artinya memiliki pengaruh terhadap JUB yang ada pada masyarakat, namun perlu diinget bahwa permintaan atas uang juga harus berkurang.

\footnotetext{
${ }^{30}$ Suhartono, "Peran Bank Sentral Dalam Stabilitas Sistem Keuangan (SSK) Dan Implementasi Jaring Pengaman Sektor Keuangan”, Jurnal Keuangan dan Perbankan, Vol 13, No.3, September 2009, Hlm 521

${ }^{31}$ Sahabudin Sidiq, "Stabilitas Permintaan Uang Di Indonesia: Sebelum Dan Sesudah Perubahan Sistem Nilai Ukur", Jurnal Ekonomi Pembangunan Vol. 10 No. 1 April 2005,Hlm 32

${ }^{32}$ Nasiti Ninda Lintangsari, "Analisis Pengaruh Instrumen Pembayaran Non Tunai Terhadap Stabilitas Sistem Keuangan Di Indonesia https://ejournal.undip.ac.id/index.php/dinamika_pembangunan/article/download/18772/13125
} 


\section{Penutup}

Kegiatan financial technology atau khususnya pengguana electronic wallet memiliki dua sisi pengaruh terhadap keuangan Indonesia. Selama kegiatan bentuk apapun dalam hal financial technology sesuai dengan Peraturan Bank Indonesia Nomor 20/6/2018 maka pelaksanaan electronic wallet akan memberikan keuntungan bagi kegiatan keuangan. Namun untuk sejauh ini berdasarkan laporan Bank Indonesia mengenai grafik peredaran uang, penggunaan electronic wallet tidak mempengaruhi secara signifikan terhadap berkurangnya peredaran rupiah di masyarakat. Walaupun dengan segala kekurangan yang masih dimiliki electronic wallet di Indonesia, namun penggunaan electronic wallet cenderung lebih efektif dan efisien dibandingkan pembayaran dengan model konvensional seperti sebelumnya dimana pengaruh penerapan uang elektronik ini dapat merubah fungsi permintaan uang yang selanjutnya dapat menurunkan jumlah rat-rata uang tunai yang beredar di masyarakat. Kedua aplikasi electronic wallet milik financial technology dan perusahaan BUMN memiliki sayarat, ketentuan, produk serta cara masing-masing yang ditawakan kepada pengguna. Walaupun pada dasarnya syarat dan ketentuan kedua produk electronic wallet dari dua perusahaan yang berbeda ini sama. Hanya saja jika pengguna lebih memilih untuk menggunakan electronic wallet milik perusahaan BUMN tentu akan mengurangi resiko yang dapat terjadi terhadap electronic wallet milik perusahaan financial technology yang kepemilikan saham oleh investor asing lebih tinggi, berbeda dengan perusahaan BUMN, yang kepemilikan sahamnya control utama tetap pada pemerintah, bukan hanya berdasarkan kebijakan masing-masing perusahaan.

Perlu adanya peningkatan kualitas electronic wallet miliki perusahaan BUMN untuk meningkatkan ketertarikan pengguna electronic wallet atas perusahaan BUMN. Peningkatan keamanan atas privasi dan data pengguna, serta peningkatan pengawasan atas kegiatan electronic wallet agar tetap sesuai dengan apa yang diatur Peraturan Perundang-Undangan dan Bank Indonesia. 


\section{Daftar Pustaka}

Adrian Sutawijaya, (2012), Pengaruh Faktor Ekonomi Terhadap Inflasi di Indonesia, Jakarta : Penerbit Univesitas Terbuka.

Bank Indonesia, (2007), Stabilitas Sistem Keuangan, Jakarta : Bank Indonesia.

Emma Santi,Budiharto, Hendro Saptono, (2017), Pengawasan otoritas Jasa Keuangan Terhadap Financial Technology (peraturan Otoritas Jasa Keuangan Nomor 77/POJK.01/2016), Diponegoro Law Journal, Volume 6 Nomor 3 Tahun 2017

Muhammad,Abdulkadir, (2004), Hukum dan Penelitian Hukum, Bandung:Citra Aditya Bakti.

Peraturan Bank Indonesia Nomor 20/6/2018 Tentang uang Elektronik Tambahan Lembar Negara Republik Indonesia nomor 6203

Rachmadi Usman, (2017), Karakteristik Uang Elektronik Dalam Sistem Pembayaran, Yuridika Universitas Airlangga, Volume 32, Nomor 1.

Rifqy Tazkiyyaturrohmah, (2018), Eksistensi Uang Elektronik Sebagai Alat Transaksi Keuangan Modern, Muslim Heritage Volume 3, Nomor 1, Mei.

Sahabudin Sidiq, (2005), Stabilitas Permintaan Uang Di Indonesia: Sebelum Dan Sesudah Perubahan Sistem Nilai Ukur, Jurnal Ekonomi Pembangunan Vol. 10 No. 1 April.

Suhartono, (2009), Peran Bank Sentral Dalam Stabilitas Sistem Keuangan (SSK) Dan Implementasi Jaring Pengaman Sektor Keuangan, Jurnal Keuangan dan Perbankan, Vol 13, No.3, September.

\section{Website}

Bank Indonesia, Indikator Sistem Pembayaran,https://www.bi.go.id/id/sistempembayaran/indikator/uang-kartal/Contents/Default.aspx

----, Jumlah Transaksi Uang Elektronik Beredar, https://www.bi.go.id/id/pencarian/Default.aspx?k=Transaksi\%20Uang\%20Elektronik

Membuka Potensi Sumber Daya Keuangan Dalam Negeri: Peran Lembaga Non Bank, http://siteresources.worldbank.org/INTINDONESIA/Resources/Publication/2800161168483675167/NBFIExe_Bhs.pdf

Nasiti Ninda Lintangsari, "Analisis Pengaruh Instrumen Pembayaran Non Tunai Terhadap Stabilitas Sistem $\quad$ Keuangan Di Indonesia https://ejournal.undip.ac.id/index.php/dinamika_pembangunan/article/download/18772/ 13125

Perkembangan Sistem Pembayaran di Indonesia,https://www.bi.go.id/id/sistempembayaran/di-indonesia/perkembangan/Contents/Default.aspx

$\begin{array}{llll}\text { PPG DALAM } & \text { JABATAN," } & \text { PPG }\end{array}$ RISTEKDIKTI,https://ppg.spada.ristekdikti.go.id/master/mod/resource/view.php?id=7 942

Kekurangan Tunai vs Keuntungan Nontunai," $16 \quad$ Februari 2017, http://www.nontunai.com/kekurangan-tunaivs-keuntungan-nontunai/ 
Daftar Dompet Digital, https://databoks.katadata.co.id/datapublish/2019/08/23/inilah-daftardompet-digital-terbesar-di-indonesia

Dompet elktronik di Indonesia, https://iprice.co.id/trend/insights/e-wallet-terbaik-diindonesia/

Aulia Annaisabiru, Teori Permintaan dan Penawaran Uang, https://blog.ruangguru.com/ ekonomi-kelas-11-teori-permintaan-dan-penawaran-uang.

Definisi dompet elektronik, https:// economictimes.indiatimes.com/definition/e-wallets.

Asing Tidak Bisa Kuasi BUMN Terbuka, Media DJKN, https://www.djkn.kemenkeu.go.id/berita_media/baca/12680/Asing-Tidak-Bisa-KuasaiBUMN-Terbuka.html.

Mochtar Riady: Saham Kami Tinggal 30 Persen di OVO, https://www.cnnindonesia.com/ekonomi/20191128131258-92-452278/mochtar-riadysaham-kami-tinggal-30-persen-di-ovo.

Databoks Katadata Indonedia, "GoPay Uang Elektronik Terpopuler di Indonesia," dikutip dari https://databoks.katadata.co.id/data publish/2018/02/13/go-pay-uang-elektronikterpopuler-di-indonesia 